\title{
Association between environmental predisposing risk factors and leg disorders in broiler chickens ${ }^{1,2}$
}

\author{
E. Tullo, $*$ I. Fontana, $* 3$ A. Peña Fernandez, $\dagger$ \\ E. Vranken, $\uparrow \uparrow$ T. Norton, $\uparrow$ D. Berckmans, $\uparrow$ and M. Guarino*
}

\begin{abstract}
*Department of Health, Animal Science and Food Safety (VESPA), Faculty of Veterinary Medicine, Università degli Studi, Milan, 20133, Italy; † Department of Biosystems, Division Animal and Human Health Engineering, M3 BIORES, Katholieke Universiteit Leuven, Leuven, 3001, Belgium; and \$Fancom BV, Panningen, NL-5980, The Netherlands
\end{abstract}

\begin{abstract}
Footpad dermatitis and lameness are a major welfare concern in broiler chicken farming. In general, footpad lesions are linked to poor environmental conditions. Ulcers that arise from advanced lesions can negatively affect the gait of the birds, with effects on the animal welfare, including, in the worst cases, inability to reach the feed or water. In this study, the degree of footpad dermatitis and lameness was manually scored on 4 broiler farms across Europe, as part of an EU-wide welfare assessment program. The welfare of the chickens was assessed 3 times per production cycle (at wk 3, 4, and 5), scoring footpad dermatitis, lameness, and litter quality. In the same broiler farms, variables such as air temperature and relative humidity were automatically measured over the same period. These variables were combined into a widely accepted thermal comfort index and associated to upper and
\end{abstract}

lower thresholds, which made it possible to quantify the percentage of time the birds spent out of the thermal comfort zone (POOC). The data was analyzed by combining data from the welfare assessments with environmental data collected by the automated monitoring systems. Considering the comparison between POOC classes, the highest probabilities of footpad dermatitis and lameness were obtained when POOC values exceeded the $70 \%$ threshold. Therefore, the analysis showed that footpad dermatitis and lameness were more frequent when the flock was exposed to poor environmental conditions for prolonged periods $(P<0.001)$. Since environmental conditions can be continuously measured, and the risk factor for footpad dermatitis and lameness increases with poor environmental conditions, there is the possibility to develop a detection and control system of severe lesions.

Key words: footpad dermatitis, intensive poultry farming, precision livestock farming, risk factor, thermal comfort

$\begin{array}{lr}\text { (C) } 2017 \text { American Society of Animal Science. All rights reserved. } & \text { J. Anim. Sci. 2017.95:1512-1520 } \\ \text { doi: } 10.2527 / \text { jas2016.1257 }\end{array}$

\section{INTRODUCTION}

Broilers are the fastest-growing and cheapest sources of animal protein among farmed species; their

\footnotetext{
${ }^{1}$ We acknowledge the support of Gemma Richards, Steve Brown, Henk Gunnink, and Deborah Temple who carried out the assessments on the farm. We also acknowledge the support of Tom Van Hertem and Luc Rooijakkers that provided environmental data.

${ }^{2}$ This project was funded by the European project no: 311825 EU-PLF (Animal and farm-centric approach to precision livestock farming in Europe), co-financed by the European Commission.

${ }^{3}$ Corresponding author: ilaria.fontana@unimi.it

Received November 30, 2016.

Accepted January 22, 2017.
}

performance is heavily conditioned by environmental parameters such as indoor air temperature, relative humidity, litter quality and ventilation speed (Fontana et al., 2015). Genetic selection for fast growth is known to be influential on leg disorders (Bassler et al., 2013), but several studies linked them to poor environmental conditions (Knowles et al., 2008; Purswell et al., 2012; Kyvsgaard et al., 2013). Footpad dermatitis (FPD) and lameness (LMNS) have a significant impact on animal welfare and economic aspects in intensive broiler farming (Cengiz et al., 2012; Kyvsgaard et al., 2013). Advanced lesions can negatively affect the walking ability of the birds, causing unnatural biomechanical forces and therefore gait alteration (Nääs et al., 2009) with potential effects on the animals' welfare. 
Table 1. Description of farms involved in the study

\begin{tabular}{|c|c|c|c|c|c|c|}
\hline Round & 1 & 2 & 3 & 4 & 5 & 6 \\
\hline \multicolumn{7}{|c|}{ Farm 1: North EU- Floor area $1298 \mathrm{~m}^{2}$} \\
\hline Date placed & Dec-2104 & Feb-2015 & Apr-2015 & Aug-2015 & $\mathrm{n} / \mathrm{a}$ & $\mathrm{n} / \mathrm{a}$ \\
\hline Season & Winter & Winter & Spring & Spring & $\mathrm{n} / \mathrm{a}$ & $\mathrm{n} / \mathrm{a}$ \\
\hline Breed & Ross 308 & Ross 308 & Ross 308 & Ross 308 & $\mathrm{n} / \mathrm{a}$ & $\mathrm{n} / \mathrm{a}$ \\
\hline \multicolumn{7}{|c|}{ Farm 2: North EU- Floor area $2240 \mathrm{~m}^{2}$} \\
\hline Date placed & Jan-2014 & Aug-2014 & Jan-2015 & Mar-2015 & Jun-2015 & Aug-2015 \\
\hline Season & Winter & Summer & Winter & Spring & Summer & Summer \\
\hline Breed & Ross 708 & Ross 708 & Ross 308 & Ross 308 & Ross 308 & Ross 308 \\
\hline \multicolumn{7}{|c|}{ Farm 3: South EU- Floor area $2300 \mathrm{~m}^{2}$} \\
\hline Date placed & Apr-2015 & Jun-2015 & Aug-2015 & Oct-2015 & $\mathrm{n} / \mathrm{a}$ & $\mathrm{n} / \mathrm{a}$ \\
\hline Season & Spring & Summer & Summer & Autumn & $\mathrm{n} / \mathrm{a}$ & $\mathrm{n} / \mathrm{a}$ \\
\hline Breed & Ross 708 & Ross 708 & Ross 708 & Ross 708 & $\mathrm{n} / \mathrm{a}$ & $\mathrm{n} / \mathrm{a}$ \\
\hline \multicolumn{7}{|c|}{ Farm 4: South EU- Floor area $1560 \mathrm{~m}^{2}$} \\
\hline Date placed & Sep-2014 & Nov-2014 & Jan-2015 & Mar-2015 & $\mathrm{n} / \mathrm{a}$ & $\mathrm{n} / \mathrm{a}$ \\
\hline Season & Autumn & Autumn & Winter & Spring & $\mathrm{n} / \mathrm{a}$ & $\mathrm{n} / \mathrm{a}$ \\
\hline Breed & Ross 708 & Ross 708 & Ross 708 & Ross 708 & $\mathrm{n} / \mathrm{a}$ & $\mathrm{n} / \mathrm{a}$ \\
\hline
\end{tabular}

Welfare assessment in broilers (Welfare Quality, 2009) is based on manual scoring, requires a lot of trained manpower and it is time-consuming (Dawkins et al., 2009; Aydin et al., 2010; Fontana et al., 2016), and could potentially create biosecurity risks moving assessors between farms (Dawkins et al., 2009). Precision Livestock Farming (PLF) can combine information technologies into on-line automated tools that can be used to control, monitor and model the behavior of animals and their biological response (Tullo et al., 2013) without stressing, disturbing or handling the animals (Wathes et al., 2008).

Due to the strong connection between leg disorders, litter quality and thermal comfort (Dawkins et al., 2004; Haslam et al., 2007; Knowles et al., 2008), the aim of this study was to find the association between environmental predisposing factors, measured in continuous (such as air temperature and relative humidity) and leg problems, manually scored during the welfare assessment procedure, to develop an automated prediction system to detect lesions.

\section{MATERIALS AND METHODS}

\section{Data Collection-Welfare Assessment}

The study was conducted in commercial farms where broilers were reared according to the EU regulation 2007/43/CE. Moreover, the animals were carefully manipulated by trained assessors following the guideline of the Welfare Quality protocol (Welfare Quality, 2009). In this study 18 traditional intensive, indoorreared, broiler chicken flocks were inspected between January 2014 to October 2015 in 4 countries, 2 located in the North and 2 located in the South of Europe (Table
1). Housing and management in the 4 farms involved in the study was very similar. The reared animals were all fast-growing hybrid broilers (Ross 308 or Ross 708) and the microclimate was controlled by the same climate system (Fancom BV, Panningen, The Netherlands)

Data regarding FPD, LMNS, and litter quality (LQ) were manually collected on 4 broiler farms. The assessments of animal welfare have been conducted at wk 3, 4, and 5 of age of the birds following the Welfare Quality (WQ) protocol on 18 broiler flocks.

Footpad dermatitis (FPD) is characterized as a contact dermatitis on the skin of the foot, both on the central pad and on the toes; the skin turns dark by contact with litter and consequently deep skin lesions can result. The WQ protocol scoring scale, from 0 to 4 (no lesions to severe lesions), allows the assessment of the severity of these injuries (Welfare Quality, 2009).

Lameness (LMNS) is defined as the inability to use 1 or both limbs in a normal manner. It can vary in severity, ranging from reduced ability or inability to bear weight, to total immobility. The WQ protocol scoring scale from 0 to 5 (normal to incapable of walking), allows the assessment of absence/presence of lameness (Welfare Quality, 2009).

Litter quality (LQ) is evaluated to define the good housing conditions; this parameter is manually assessed and scored as good (completely dry and flaky, score 0 ) or poor (sticky and wet, score 4 ) according to the WQ protocol.

For FPD and LMNS the outcomes of the WQ assessments were transformed into binary variables indicating the absence/presence of lesions (0 and 1). Assessment scores $\geq 2$ were considered as a thresh- 
Table 2. Optimal air temperature-relative humidity ranges for Broiler at different ages (ROSS 708 Management Handbook (Aviagen, modified)

\begin{tabular}{|c|c|c|c|c|c|c|c|c|}
\hline \multirow{2}{*}{$\begin{array}{l}\text { Age of } \\
\text { birds, d }\end{array}$} & \multirow[b]{2}{*}{ Variable } & \multicolumn{5}{|c|}{ Relative humidity, \% } & \multicolumn{2}{|c|}{ THI ranges } \\
\hline & & 40 & 50 & 60 & 70 & 80 & Lower & Upper \\
\hline \multirow[t]{2}{*}{1} & Temperature & $36^{\circ} \mathrm{C}$ & $33^{\circ} \mathrm{C}$ & $31^{\circ} \mathrm{C}$ & $29^{\circ} \mathrm{C}$ & $27^{\circ} \mathrm{C}$ & 78 & 84 \\
\hline & THI ${ }^{1}$ & 84 & 82 & 81 & 80 & 78 & & \\
\hline \multirow[t]{2}{*}{3} & Temperature & $34^{\circ} \mathrm{C}$ & $31^{\circ} \mathrm{C}$ & $29^{\circ} \mathrm{C}$ & $27^{\circ} \mathrm{C}$ & $26^{\circ} \mathrm{C}$ & 76 & 81 \\
\hline & THI & 81 & 80 & 78 & 77 & 76 & & \\
\hline \multirow[t]{2}{*}{6} & Temperature & $33^{\circ} \mathrm{C}$ & $30^{\circ} \mathrm{C}$ & $28^{\circ} \mathrm{C}$ & $26^{\circ} \mathrm{C}$ & $24^{\circ} \mathrm{C}$ & 73 & 80 \\
\hline & THI & 80 & 78 & 77 & 75 & 73 & & \\
\hline \multirow[t]{2}{*}{9} & Temperature & $31^{\circ} \mathrm{C}$ & $29^{\circ} \mathrm{C}$ & $27^{\circ} \mathrm{C}$ & $25^{\circ} \mathrm{C}$ & $23^{\circ} \mathrm{C}$ & 72 & 78 \\
\hline & THI & 78 & 76 & 75 & 74 & 72 & & \\
\hline \multirow[t]{2}{*}{12} & Temperature & $30^{\circ} \mathrm{C}$ & $28^{\circ} \mathrm{C}$ & $26^{\circ} \mathrm{C}$ & $24^{\circ} \mathrm{C}$ & $23^{\circ} \mathrm{C}$ & 72 & 77 \\
\hline & THI & 77 & 75 & 74 & 72 & 72 & & \\
\hline \multirow[t]{2}{*}{15} & Temperature & $29^{\circ} \mathrm{C}$ & $27^{\circ} \mathrm{C}$ & $25^{\circ} \mathrm{C}$ & $23^{\circ} \mathrm{C}$ & $22^{\circ} \mathrm{C}$ & 70 & 75 \\
\hline & THI & 75 & 74 & 72 & 71 & 70 & & \\
\hline \multirow[t]{2}{*}{18} & Temperature & $28^{\circ} \mathrm{C}$ & $26^{\circ} \mathrm{C}$ & $24^{\circ} \mathrm{C}$ & $22^{\circ} \mathrm{C}$ & $21^{\circ} \mathrm{C}$ & 68 & 74 \\
\hline & THI & 73 & 71 & 70 & 68 & 67 & & \\
\hline \multirow[t]{2}{*}{21} & Temperature & $27^{\circ} \mathrm{C}$ & $25^{\circ} \mathrm{C}$ & $23^{\circ} \mathrm{C}$ & $21^{\circ} \mathrm{C}$ & $20^{\circ} \mathrm{C}$ & 67 & 73 \\
\hline & THI & 73 & 71 & 70 & 68 & 67 & & \\
\hline \multirow[t]{2}{*}{24} & Temperature & $26^{\circ} \mathrm{C}$ & $24^{\circ} \mathrm{C}$ & $22^{\circ} \mathrm{C}$ & $20^{\circ} \mathrm{C}$ & $19^{\circ} \mathrm{C}$ & 65 & 71 \\
\hline & THI & 71 & 70 & 68 & 67 & 65 & & \\
\hline \multirow[t]{2}{*}{27} & Temperature & $25^{\circ} \mathrm{C}$ & $23^{\circ} \mathrm{C}$ & $21^{\circ} \mathrm{C}$ & $19^{\circ} \mathrm{C}$ & $18^{\circ} \mathrm{C}$ & 64 & 70 \\
\hline & THI & 70 & 69 & 67 & 65 & 64 & & \\
\hline
\end{tabular}

${ }^{1} \mathrm{THI}=$ temperature humidity index, calculated as $1.8 \times \mathrm{T}-[(1-\mathrm{RH} /$ $100) \times(\mathrm{T}-14.3)]+32$, reported in bold .

old for the presence of severe lesions, in this way both mild and severe lesions were grouped together.

According to this criteria (WQ litter score $\geq 2$ ), also the LQ was expressed as a binary variable and defined as good or poor.

The application of these thresholds was necessary to make more homogenous the original parameters assessed that were highly skewed.

\section{Data Collection-Environmental Parameters}

The climate control in all the farms considered in the study was completely automated. For this study, the climate variables collected 24/7 were: maximum and minimum air temperature inside and outside the barn and relative humidity. Calibrated relative humidity (RHM.2RHO/2 Sensor) and air temperature (SF.7 Temp Sensor) sensors were installed on the farm by the PLF technology provider (Fancom BV, Panningen, The Netherlands).

Raw data from the sensors were collected every 15 min with FarmManager (Fancom BV, Panningen, The Netherlands) and then automatically uploaded and stored into an online data server.

\section{Data Editing and Statistical Analysis}

Data of FPD, LMNS, and LQ manually assessed with the WQ protocol were merged with climate data continuously collected by farm sensors. All the rounds included in the data collection were used in the statistical analysis. In total, there were 18 complete rounds available in 4 farms with WQ assessment and environmental data.

Broilers are reared under different air temperature and relative humidity ranges according to their age (Aviagen, 2014) and a tightly controlled environment improves animal health, well-being, and production efficiency. Therefore, according to relative humidity variation, the air temperature should be higher at the beginning and gradually lowered toward the end of the cycle. Thermal comfort indices such as temperature-humidity index (THI) have been developed to assess the impact of the thermal environment on thermoregulatory status on different species (Purswell et al., 2012). In this study the same formula was used to identify the optimal THI ranges for fast growing broilers, based on reference values for air temperature and relative humidity found on the ROSS Management Handbook (Aviagen, 2014) and reported in Table 2.

Temperature-humidity index (THI) was used to find a relation between leg disorders and environmental conditions and was calculated according to the formula (Kibler, 1964):

$$
T H I=\left\{1.8 \times T-\left[\left(\frac{1-R H}{100}\right) \times(T-14.3)\right]+32\right\}
$$

combining air temperature $(\mathbf{T})$ and relative humidity $(\mathbf{R H})$ data, collected every $15 \mathrm{~min}$ by the automated system.

To estimate the percentage of time that the broilers spent out of the ranges of thermal comfort (POOC), each hour of the day was classified " 0 " when the mean hourly THI was included in the ranges expected. On the other hand, it was classified " 1 " when the mean hourly THI value was out of the optimal thermal situation. In this way it was possible to sum the hours per day spent out the thermal comfort zone in 3 reference periods for each round (Day 1 to 21, Day 1 to 28, and Day 1 to 35).The results were expressed as POOC, before each WQ assessment (performed at week 3, 4, and 5 of age).

All statistical analyses were conducted with SAS software (SAS Inst. Inc., Cary, NC). In this study, the binary responses were represented by the presence and absence of FPD and LMNS. Therefore, a mixedeffects logistic regression model using the GLIMMIX procedure with contrasts was applied to investigate the association of POOC, LQ, density of birds (DNST, $\mathrm{kg} / \mathrm{m}^{2}$ ) and age of birds with FPD and LMNS.

The model used was: 
Table 3. Descriptive statistic for dependent and independent variables considered in the analysis

\begin{tabular}{lccccc}
\hline \hline Descriptive statistic & Footpad score & Lameness score & Litter score & POOC,$\%$ & ${\text { Final bird density, } \mathrm{kg} / \mathrm{m}^{2}}^{1}$ \\
\hline Mean ( \pm SD) & $0.47( \pm 0.86)$ & $1.33( \pm 1.26)$ & $1.75( \pm 0.87)$ & $52( \pm 20)$ & $29.36( \pm 5.93)$ \\
Range & $0-4$ & $0-5$ & $0-4$ & $9-82$ & $19.8-39.5 \mathrm{~kg} / \mathrm{m}^{2}$ \\
\hline
\end{tabular}

${ }^{1} \mathrm{POOC}=$ Time spent out of the thermal comfort zone.

$$
\begin{aligned}
& \operatorname{Logit}_{\left(\mathrm{p}_{\mathrm{ijklmn}}\right)}=\mathrm{a}+\mathrm{POOC}_{\mathrm{i}}+\mathrm{LQ}_{\mathrm{j}}+\mathrm{DNST}_{\mathrm{k}} \\
& +\mathrm{bAGE}_{1}+\mathrm{FR}_{\mathrm{m}}+\mathrm{e}_{\mathrm{ijklm}}
\end{aligned}
$$

where $p_{i j k l m n}$ was the probability of FPD or LMNS occurrence; $a$ was the intercept; POOC $_{i}$ was the fixed effect of the ith class of time spent outside the thermal comfort zone ( $\mathrm{i}=4$ levels: $<40 \%, 40$ to $60 \%, 60$ to $70 \%$, and $>70 \%$ of the time), $L_{\mathrm{j}}$ was the fixed effect of the $j$ th level of litter quality ( $j=2$ levels: good and poor), DNST $_{k}$ was the fixed effect of the kth class of bird density at the moment of each WQ assessment $(\mathrm{k}=5$ levels: $<20 \mathrm{~kg} / \mathrm{m}^{2}, 20$ to $25 \mathrm{~kg} / \mathrm{m}^{2}, 25$ to $30 \mathrm{~kg} / \mathrm{m}^{2}, 30$ to $35 \mathrm{~kg} /$ $\mathrm{m}^{2},>35 \mathrm{~kg} / \mathrm{m}^{2}$ ); $\mathrm{bAGE}_{1}$ was the regression coefficient for the age $(1=1$ level, age expressed in days $)$ and FRm $(\mathrm{m}=18$ levels $)$ was the random effect of the interaction between the farm (4 levels) and the round (14 levels, as the result of the combination of month $\times$ year).

The random interaction was used to account for part of the correlations of data within groups in the model. Odds ratios and 95\% confidence intervals were estimated for each risk factor included in the analysis for FPD and LMNS. The GLIMMIX procedure was also used to plot diffograms (mean-mean scatter plot; SAS Inst. Inc., Cary, NC).

\section{RESULTS}

Average value and standard deviation of FPD, LMNS, LQ, stocking density $\left(\mathrm{kg} / \mathrm{m}^{2}\right)$, and POOC in the 4 farms considered in the analysis are reported in Table 3. These values were estimated averaging scores assigned by WQ assessors during the assessment procedure that lasted every 21,28 , and $35 \mathrm{~d}$ of broiler production cycles. Average FPD scores resulted 0.47 ( \pm 0.86 ) on a range from 0 to 4 , average LMNS score resulted $1.33( \pm 1.26)$ on a range from 0 to 5 and average LQ score resulted $1.75( \pm 0.87)$ on a range from 0 to

Table 4. Average presence of footpad dermatitis, lameness and litter quality manually assessed in the

\begin{tabular}{|c|c|c|c|c|c|}
\hline \multicolumn{2}{|c|}{$\mathrm{FPD}^{1}, \%$} & \multicolumn{2}{|c|}{$\mathrm{LMNS}^{2}, \%$} & \multicolumn{2}{|c|}{$\mathrm{LQ}^{3}, \%$} \\
\hline Presence & Absence & Presence & Absence & Poor & Good \\
\hline 14.99 & 85.01 & 23.33 & 76.67 & 62.59 & 37.41 \\
\hline
\end{tabular}
four farms considered in the analysis
4. The mean values were very close to scores of 0 and 1 indicating the good quality of the flocks investigated.

Table 4 shows the average presence of FPD, LMNS and quality of the litter manually assessed in all the rounds (defined by the month and year of the production cycles) considered in the analysis. On average, the presence of FPD and LMNS resulted lower than the $25 \%$ and the quality of the litter in the rounds investigated was generally evaluated as poor $(62.59 \%)$.

The following step was to consider FPD, LMNS, and LQ round by round (Fig. 1).

The highest value reached for FPD was $41.33 \%$, while the highest LMNS values resulted up to $100 \%$ of birds involved in the WQ assessment.

Figure 2 displays the description of rounds used in the analysis. The percentage of time spent outside the thermal comfort zone (POOC) was estimated using the combination of air temperature and $\mathrm{RH}$ automatically collected in the farm for each reference period (from chicks placement to assessment at weeks 3, 4, and 5). The mean value $(52 \%$, Table 3$)$ and the high percentages found considering each round separately (up to $82 \%$, Fig. 2), are related to the way the POOC was calculated.

The POOC was further analyzed to understand the amount of time the broiler spent below and above the thermal comfort zone. The results showed that broilers mainly spent longer periods $(>85 \%)$ above the thermal comfort zone rather than below; this indicates that broilers were more often exposed to high air temperature and high relative humidity (Table 5). So, the POOC included in the statistical analysis describes the time spent above the thermal comfort zone, furthermore there were not enough data regarding lesions when broilers were below the thermal comfort zone.

The results of the PROC GLIMMIX to evaluate the effect of risk factors associated with FPD and LMNS are displayed in Table 6.

Regarding the FPD, all the effects included in the model resulted highly significant $(P$-value $<0.01)$. For LMNS, all the effects considered in the model resulted highly significant $(P$-value $<0.001)$, except for the stocking density. The odds ratio associated to the presence, versus the absence, of PFD and LMNS tended to increase proportionally to time spent out of the thermal comfort zone.

The probabilities of having FPD and LMNS changed considerably according to the increase of time spent in an uncomfortable situation. Considering 

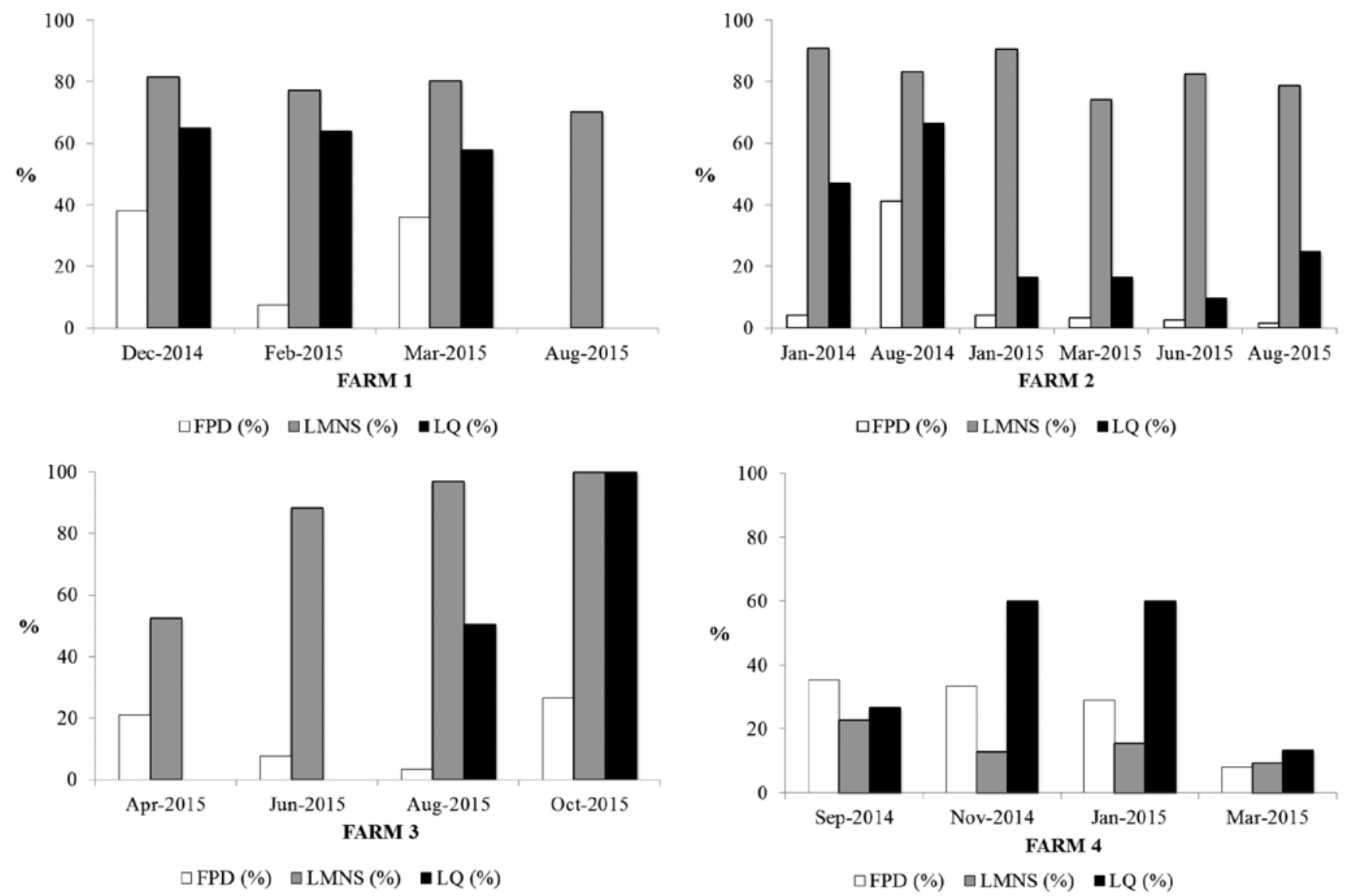

Figure 1. Average percentage of FPD, LMNS and LQ for each round collected in the 4 farms. FPD $=$ footpad dermatitis; LMNS $=$ lameness; LQ $=$ litter quality.
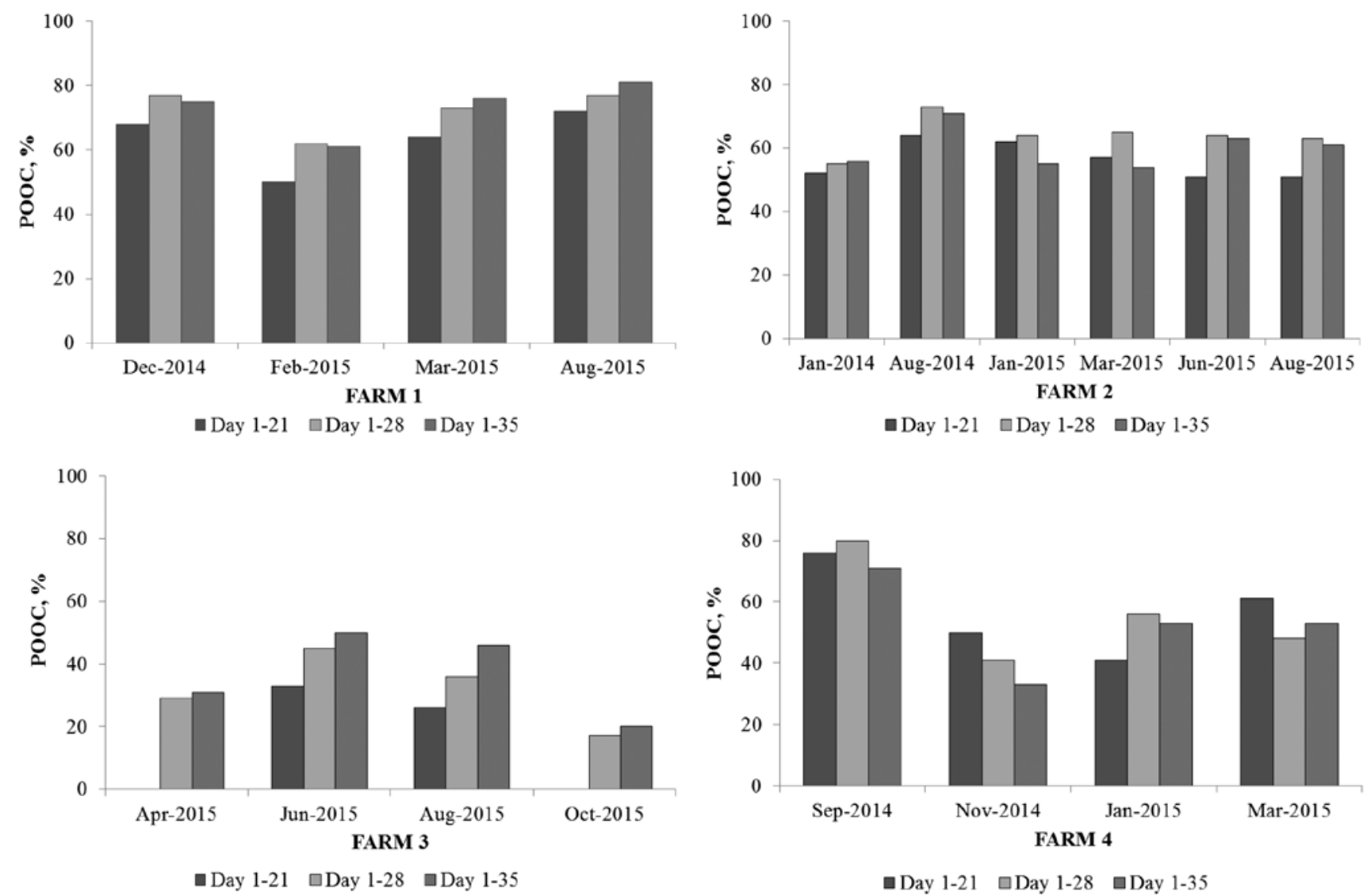

Figure 2. Description of rounds used in the analysis. Percentage of time spent outside the thermal comfort zone (POOC) for each reference period (from chick placement to assessment at wk 3, 4, and 5). 
Table 5. Time spent outside the thermal comfort zone separated into outside above and outside below

\begin{tabular}{|c|c|c|c|c|c|c|}
\hline Round & 1 & 2 & 3 & 4 & 5 & 6 \\
\hline \multicolumn{7}{|l|}{ Farm 1} \\
\hline Above the thermal comfort zone, $\%$ & 99.79 & 97.21 & 97.75 & 99.81 & $\mathrm{n} / \mathrm{a}$ & $\mathrm{n} / \mathrm{a}$ \\
\hline Below the thermal comfort zone, $\%$ & 0.21 & 2.79 & 2.25 & 0.19 & $\mathrm{n} / \mathrm{a}$ & $\mathrm{n} / \mathrm{a}$ \\
\hline \multicolumn{7}{|l|}{ Farm 2} \\
\hline Above the thermal comfort zone, $\%$ & 85.13 & 96.52 & 90.90 & 92.29 & 91.83 & 94.67 \\
\hline Below the thermal comfort zone, $\%$ & 14.87 & 3.48 & 9.10 & 7.71 & 8.17 & 5.33 \\
\hline \multicolumn{7}{|l|}{ Farm 3} \\
\hline Above the thermal comfort zone, $\%$ & 79.95 & 91.35 & 96.67 & 95.30 & $\mathrm{n} / \mathrm{a}$ & $\mathrm{n} / \mathrm{a}$ \\
\hline Below the thermal comfort zone, $\%$ & 20.05 & 8.65 & 3.33 & 4.70 & $\mathrm{n} / \mathrm{a}$ & $\mathrm{n} / \mathrm{a}$ \\
\hline \multicolumn{7}{|l|}{ Farm 4} \\
\hline Above the thermal comfort zone, $\%$ & 99.23 & 93.86 & 97.61 & 99.97 & $\mathrm{n} / \mathrm{a}$ & $\mathrm{n} / \mathrm{a}$ \\
\hline Below the thermal comfort zone, $\%$ & 0.77 & 6.14 & 2.39 & 0.03 & $\mathrm{n} / \mathrm{a}$ & $\mathrm{n} / \mathrm{a}$ \\
\hline
\end{tabular}

the comparison between POOC classes $(<40 \%, 40$ to $60 \% ; 60$ to $70 \%$, and $>70 \%$ ), the highest probabilities of FPD and LMNS were obtained when POOC values exceeded the $70 \%$ threshold; but, there was no significant difference in the development of LMNS between being out of the thermal comfort zone for 60 to $70 \%$ and for over $70 \%$ of time.

Regarding the considered variables, the age did affect significantly the presence of FPD and LMNS $(P$-value $<0.001)$.
The odds ratios associated to the presence (versus the absence) of PFD changed considerably according to the increase in stocking density $\left(\mathrm{kg} / \mathrm{m}^{2}\right)$. Considering the comparison between DNST classes $\left(<20 \mathrm{~kg} / \mathrm{m}^{2}, 20\right.$ to $25 \mathrm{~kg} / \mathrm{m}^{2}, 25$ to $30 \mathrm{~kg} / \mathrm{m}^{2}, 30$ to $35 \mathrm{~kg} / \mathrm{m}^{2}$, and $>35 \mathrm{~kg} / \mathrm{m}^{2}$ ), the highest probabilities of FPD were obtained when DNST values exceeded the $35 \mathrm{~kg} / \mathrm{m}^{2}$ threshold. Considering the $>35 \mathrm{~kg} / \mathrm{m}^{2}$ DNST class as a reference, there was no significant difference in the development of FPD when the flock

Table 6. Risk factors associated with footpad dermatitis (FPD) and lameness (LMNS)

\begin{tabular}{|c|c|c|c|c|c|c|}
\hline Variable & Parameter & Estimate & Std.Err & $P$-value ${ }^{1}$ & OR & CI95 \\
\hline \multirow[t]{12}{*}{ FPD } & Intercept & -1.057 & 0.843 & $\mathrm{~ns}$ & & \\
\hline & POOC $^{2}$ vs. $>70 \%$ & & & $* * *$ & & \\
\hline & $<40 \%$ & -3.317 & 0.477 & $* * *$ & 0.036 & $0.014-0.092$ \\
\hline & $40-60 \%$ & -1.993 & 0.358 & $* * *$ & 0.136 & $0.068-0.275$ \\
\hline & $60-70 \%$ & -0.946 & 0.330 & $* *$ & 0.404 & $0.212-0.771$ \\
\hline & Age & 0.054 & 0.015 & $* * *$ & 1.055 & $1.024-1.087$ \\
\hline & $\mathrm{DNST}^{3} \mathrm{vs}>35 \mathrm{~kg} / \mathrm{m}^{2}$ & & & $* * *$ & & \\
\hline & $<20 \mathrm{~kg} / \mathrm{m}^{2}$ & 0.432 & 0.313 & $\mathrm{~ns}$ & 0.649 & $0.352-1.199$ \\
\hline & $20-25 \mathrm{~kg} / \mathrm{m}^{2}$ & -1.103 & 0.296 & $* * *$ & 0.332 & $0.186-0.592$ \\
\hline & $25-30 \mathrm{~kg} / \mathrm{m}^{2}$ & -0.154 & 0.234 & $\mathrm{~ns}$ & 0.857 & $0.542-1.355$ \\
\hline & $30-35 \mathrm{~kg} / \mathrm{m}^{2}$ & -0.640 & 0.313 & $*$ & 0.527 & $0.286-0.973$ \\
\hline & Litter quality Poor vs. Good & -0.390 & 0.121 & $* *$ & 0.678 & $0.535-0.859$ \\
\hline \multirow[t]{12}{*}{ LMNS } & Intercept & 0.370 & 0.730 & ns & & \\
\hline & POOC vs. $>70 \%$ & & & $* * *$ & & \\
\hline & $<40 \%$ & -1.778 & 0.278 & $* * *$ & 0.169 & $0.098-0.292$ \\
\hline & $40-60 \%$ & -0.718 & 0.211 & $* * *$ & 0.488 & $0.322-0.378$ \\
\hline & $60-70 \%$ & -0.195 & 0.153 & ns & 0.823 & $0.610-1.112$ \\
\hline & Age & 0.070 & 0.011 & $* * *$ & 1.072 & $1.048-1.098$ \\
\hline & DNST vs. $>35 \mathrm{~kg} / \mathrm{m}^{2}$ & & & $\mathrm{~ns}$ & & \\
\hline & $<20 \mathrm{~kg} / \mathrm{m}^{2}$ & -0.323 & 0.282 & $\mathrm{~ns}$ & 0.724 & $0.416-1.259$ \\
\hline & $20-25 \mathrm{~kg} / \mathrm{m}^{2}$ & 0.046 & 0.230 & $\mathrm{~ns}$ & 1.047 & $0.668-1.642$ \\
\hline & $25-30 \mathrm{~kg} / \mathrm{m}^{2}$ & -0.171 & 0.208 & $\mathrm{~ns}$ & 0.843 & $0.560-1.268$ \\
\hline & $30-35 \mathrm{~kg} / \mathrm{m}^{2}$ & 0.258 & 0.228 & $\mathrm{~ns}$ & 1.294 & $0.828-2.024$ \\
\hline & Litter quality Poor vs. Good & -0.523 & 0.122 & $* * *$ & 0.593 & $0.467-0.753$ \\
\hline
\end{tabular}

$1 * * *=P<0.001, * *=P<0.01, *=P<0.05, \mathrm{~ns}=P>0.05$.

${ }^{2} \mathrm{POOC}=$ time out of the thermal comfort zone.

${ }^{3} \mathrm{DNST}=$ stocking density $(\mathrm{kg} / \mathrm{m} 2)$. 

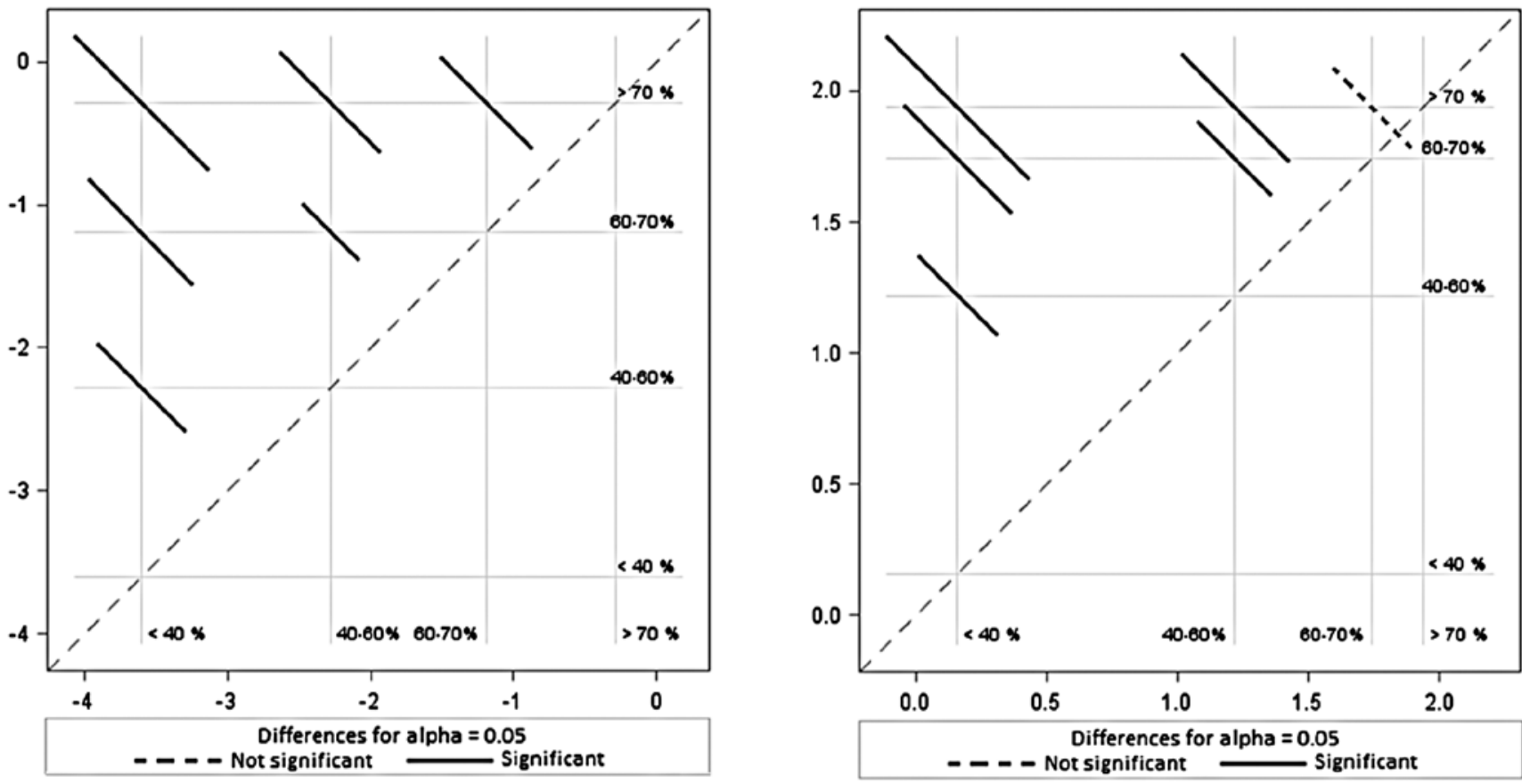

Figure 3. SAS output reporting the diffogram comparing the effect of time out of thermal comfort (POOC) on footpad dermatitis (left) and lameness (right).

density ranged between 25 and $30 \mathrm{~kg} / \mathrm{m}^{2}$. The same situation occurred for density lower than $20 \mathrm{~kg} / \mathrm{m}^{2}$.

Litter quality (LQ) resulted highly significant in all the parameters assessed, indicating the high impact of litter quality on FPD, and LMNS presence.

Graphical output (diffogram), presenting the multiple-comparison of POOC classes is provided in Fig. 3, both for FPD and LMNS. The comparison among POOC classes revealed that each class had significant different effect (black lines) on the presence of FPD (Fig. 3, left). This comparison was similar for LMNS (Fig. 3, right), but there is no significant difference (dashed line) on the occurrence of LMNS in broiler comparing POOC classes of 60 to $70 \%$ and $>70 \%$. The $45^{\circ}$ reference line indicates whether the 2 least-square means are significantly different. Each line drawn at an intersection of 2 means corresponds to the $95 \%$ confidence interval of the difference of the 2 least-square means in the comparison. If the interval crosses the reference line, such a comparison is not significant at the $5 \%$ level.

\section{DISCUSSION}

Modern breeds of broilers have been heavily selected for high juvenile growth rate, breast-meat yield and efficiency of feed conversion, but this has left them vulnerable to welfare problems such as susceptibility to cardio-vascular disease and lameness or difficulty in walking (Dawkins and Layton, 2012; Rizzi et al., 2013). Several studies linked leg disorders to poor environmental conditions (Knowles et al., 2008; Purswell et al., 2012; Kyvsgaard et al., 2013). Indeed, broilers can tolerate a wide range of relative humidity and still perform efficiently, but changes in relative humidity can rapidly and negatively influence litter conditions that have been associated with lowered carcass quality and increased leg and foot abnormalities (Weaver and Meijerhof, 1991). The occurrence of leg disorders is influenced by genetic strain, sex, stocking density, and weight gain as well as by management factors such as lighting programs and rearing conditions including the thickness of the bedding, the presence of ammonia, and the moisture in the litter (Nääs et al., 2009; Kyvsgaard et al., 2013). Reduced walking or standing ability often leads to breast blisters and hock burn because the birds spend a long time crouching on poor-quality litter.

The aim of this study was to find the association between environmental predisposing factors continuously measured and leg disorders, manually scored during the welfare assessment procedure, to develop an automated prediction system to detect those lesions since automated systems have been widely used to monitor the behavior, position and activity (Aydin et al., 2010; Peña Fernández et al., 2015), growth (Fontana et al., 2015), and welfare (Dawkins et al., 2012; Fontana et al., 2016) of broiler chickens.

The results of the present study showed that POOC, LQ, DNST $\left(\mathrm{kg} / \mathrm{m}^{2}\right)$ and age of birds were significant predisposing factors for the development of FPD and LMNS in broilers.

In the farms considered in this study, the average score for FPD resulted close to 0, and therefore, it was not a surprise to observe a general good flock quality. 
Good management practices aimed to the reduction of FPD prevalence positively influenced the overall flock quality. Also LMNS average scores resulted quite low (close to 1), even if the proportion of lame birds resulted high. The High LMNS presence was related to the threshold used to classify birds; indeed, birds with score $\geq 2$ were considered as lame, including both mild and severe lameness. Moreover, several studies have indicated that broiler weight might be an important determinant of lameness, since the birds become lamer more or less linearly the heavier and the elder they became (Kestin et al., 2001). The findings in the commercial farms included in this study might be considered as normal, since the current literature describes a relatively high incidence of fast growth rates associated to leg weakness and gait alteration in broilers (Nääs et al., 2009).

Our study stressed the importance of being continuously in optimal thermal conditions; POOC values resulted very high (up to $82 \%$ ), but such high percentages were due to how the POOC was evaluated and not due to poor farm management.

Since the aim of this work was to estimate the cumulative effect of time spent out of the thermal comfort zone, even small deviations from the optimal ranges were considered as a discomfort situation.

The POOC parameter showed how the poor environmental conditions (both high air temperature and relative humidity) might negatively affect the welfare of the birds. Longer periods spent in uncomfortable situations were associated to increased odds of having FPD and LMNS. Being out of the recommended ranges for more than $70 \%$ of the time compared to shorter periods $(<40 \%, 40$ to $60 \%, 60$ to $70 \%)$ led to risk probability of having FPD respectively of 28,7 , and 3 times greater. The same comparison was also made for LMNS and showed a similar trend. The risk probabilities of developing LMNS were 6, 2, and 1 times greater when the birds spent longer periods ( $\geq 70 \%$ ) out of the thermal comfort zone compared to shorter periods. This was in line to what was reported by (Martrenchar et al., 2002), who observed a positive correlation between the prevalence of foot-pad dermatitis and the percentage of moisture in the air. The results were also in accordance with Dawkins et al. (2004) who found that the number of birds that were not lame (gait 0 ) was correlated with the percentage of time that birds spent in the thermal comfort zone. Furthermore, improper environmental condition may result in poor LQ, commonly associated with increased ammonia burns on the breasts and swollen foot pads (Weaver and Meijerhof, 1991).

Our study stressed the importance of litter quality on the development of FPD because it was an important predictor for high FPD and LMNS scores. The general trend of the odds ratio relative to the litter quality indicated that a higher quality (scored 0 and 1) was associated to a reduced odd in having lame birds or birds with lesions. As expected, poor litter quality would led to an increase in contact dermatitis (Kestin et al., 2001; Kyvsgaard et al., 2013).

The age is another risk factor associated to the presence of lesions and to the lameness of broilers; indeed, the increase of the weight (strictly correlated with the age) reduces the mobility of the broilers and increases the possibility of having footpad lesions and lame birds (Kestin et al., 2001; Knowles et al., 2008; Kyvsgaard et al., 2013).

Increased FPD was associated with higher stocking density. Stocking density had a direct effect on FPD and this effect is most likely to be higher at the end of the growing period, when the increased size or weight density of the birds may become more important than their number (Hepworth et al., 2010). This was confirmed by the results of this study, in which higher stocking densities were associated to increased probabilities of having FPD. The relation between FPD and stocking density is already known, since greater density of birds would be likely to cause poorer litter quality due to the production of large volume of feces, with a resulting increase in contact dermatitis (Haslam et al., 2007).

On the other hand, stocking density had no significant effect on LMNS, and although it affects chicken welfare, stocking density per se is less important than other factors (Dawkins et al., 2004), since commercial broiler genotypes tend to normally develop LMNS (Nääs et al., 2009).

The results of the present study showed that the increase of the age of birds and the time spent outside the thermal comfort zone associated with a reduced quality of the litter, represent a high risk factor for broilers to incur severe lesions. The potential association between automated control of the environmental conditions and the welfare assessments might be the basis for the development of models and algorithms capable to automatically detect thresholds above which lesions are mostly probable. Automated and IT systems have been widely used to monitor the behavior, position and activity, growth, and welfare of broiler chickens. The advantage of these monitoring systems is the continuous collection of information without stressing, disturbing or handling the animals. Moreover, the combination of cheap technology and relative simple statistical analysis of group behavior can quickly and easily provide valuable information from a large data set, having potential for wide application in animal husbandry.

Furthermore, the automation of the assessment procedure could improve the welfare of the broilers, reducing the costs and the response time in case of problems in the farm. 


\section{LITERATURE CITED}

Aviagen. 2014. ROSS Broiler management handbook. Huntsville, AL. p. 19.

Aydin, A., O. Cangar, S. E. Ozcan, C. Bahr, and D. Berckmans. 2010. Application of a fully automatic analysis tool to assess the activity of broiler chickens with different gait scores. Comput. Electron. Agric. 73:194-199. doi:10.1016/j.compag.2010.05.004

Bassler, A. W., C. Arnould, A. Butterworth, L. Colin, I. C. De Jong, V. Ferrante, P. Ferrari, S. Haslam, F. Wemelsfelder, and H. J. Blokhuis. 2013. Potential risk factors associated with contact dermatitis, lameness, negative emotional state, and fear of humans in broiler chicken flocks. Poult. Sci. 92:2811-2826. doi:10.3382/ps.2013-03208

Cengiz, Ö., B. H. Köksal, A. G. Önol, O. Tatli, Ö. Sevim, H. Avci, and S. F. Bilgili. 2012. Influence of dietary enzyme supplementation of barley-based diets on growth performance and footpad dermatitis in broiler chickens exposed to early high-moisture litter. JAPR. 21:117-125. doi:10.3382/japr.2011-00447

Dawkins, M. S., R. Cain, and S. J. Roberts. 2012. Optical flow, flock behaviour and chicken welfare. Anim. Behav. 84:219223. doi:10.1016/j.anbehav.2012.04.036

Dawkins, M. S., C. A. Donnelly, and T. A. Jones. 2004. Chicken welfare is influenced more by housing conditions than by stocking density. Nature 427:342-344. doi:10.1038/nature02226

Dawkins, M. S., and R. Layton. 2012. Breeding for better welfare: Genetic goals for broiler chickens and their parents. Anim. Welf. 21:147-155. doi:10.7120/09627286.21.2.147

Dawkins, M. S., H.-J. Lee, C. D. Waitt, and S. J. Roberts. 2009. Optical flow patterns in broiler chicken flocks as automated measures of behaviour and gait. Appl. Anim. Behav. Sci. 119:203-209. doi:10.1016/j.applanim.2009.04.009

Fontana, I., E. Tullo, A. Butterworth, and M. Guarino. 2015. An innovative approach to predict the growth in intensive poultry farming. Comput. Electron. Agric. 119:178-183. doi:10.1016/j.compag.2015.10.001

Fontana, I., E. Tullo, A. Scrase, and A. Butterworth. 2016. Vocalisation sound pattern identification in young broiler chickens. Animal 10:1567-1574. doi:10.1017/S1751731115001408

Haslam, S. M., T. G. Knowles, S. N. Brown, L. J. Wilkins, S. C. Kestin, P. D. Warriss, and C. J. Nicol. 2007. Factors affecting the prevalence of foot pad dermatitis, hock burn and breast burn in broiler chicken. Br. Poult. Sci. 48:264-275. doi:10.1080/00071660701371341

Hepworth, P. J., A. V. Nefedov, I. B. Muchnik, and K. L. Morgan. 2010. Early warning indicators for hock burn in broiler flocks. Avian Pathol. 39:405-409. doi:10.1080/03079457.2010.510500
Kestin, S. C., S. Gordon, G. Su, and P. Sørensen. 2001. Relationships in broiler chickens between lameness, liveweight, growth rate and age. Vet. Rec. 148:195-197. doi:10.1136/vr.148.7.195

Kibler, H. 1964. Thermal effects of various temperature-humidity combinations on Holstein cattle as measured by eight physiological responses. MO Agr. Exp. Research Bulletin, 862: 1-42.

Knowles, T. G., S. C. Kestin, S. M. Haslam, S. N. Brown, L. E. Green, A. Butterworth, S. J. Pope, D. Pfeiffer, and C. J. Nicol. 2008. Leg disorders in broiler chickens: Prevalence, risk factors and prevention. PLoS One 3:e1545. doi:10.1371/journal.pone.0001545

Kyvsgaard, N. C., H. B. Jensen, T. Ambrosen, and N. Toft. 2013. Temporal changes and risk factors for foot-pad dermatitis in Danish broilers. Poult. Sci. 92:26-32. doi:10.3382/ps.2012-02433

Martrenchar, A., E. Boilletot, D. Huonnic, and F. Pol. 2002. Risk factors for foot-pad dermatitis in chicken and turkey broilers in France. Prev. Vet. Med. 52:213-226. doi:10.1016/S01675877(01)00259-8

Nääs, I., I. C. L. A. Paz, M. Baracho, A. Menezes, L. Bueno, I. Almeida, and D. Moura. 2009. Impact of lameness on broiler well-being. JAPR. 18:432-439.

Peña Fernández, A., E. Tullo, V. Exadaktylos, E. Vranken, M. Guarino, and D. Berckmans. 2015. Broiler activity and distribution as behaviour-based welfare indicators Precision Livestock Farming 2015- Papers Presented at the 7th European Conference on Precision Livestock Farming, ECPLF 2015. p. 208-217.

Purswell, J. L., W. A. Dozier, III, H. A. Olanrewaju, J. D. Davis, H. Xin, and R. S. Gates. 2012. Effect of temperature-humidity index on live performance in broiler chickens grown from 49 to 63 days of age. In: 2012 IX International Livestock Environment Symposium (ILES IX). p. 3.

Rizzi, C., B. Contiero, and M. Cassandro. 2013. Growth patterns of Italian local chicken populations. Poult. Sci. 92:22262235. doi:10.3382/ps.2012-02825

Tullo, E., I. Fontana, and M. Guarino. 2013. Precision livestock farming: An overview of image and sound labelling. In: Precision Livestock Farming 2013- Papers Presented at the 6th European Conference on Precision Livestock Farming, ECPLF 2013. p. 30-38.

Wathes, C. M., H. H. Kristensen, J. M. Aerts, and D. Berckmans. 2008. Is precision livestock farming an engineer's daydream or nightmare, an animal's friend or foe, and a farmer's panacea or pitfall? Comput. Electron. Agric. 64:2-10. doi:10.1016/j.compag.2008.05.005

Weaver, W. D., Jr., and R. Meijerhof. 1991. The effect of different levels of relative humidity and air movement on litter conditions, ammonia levels, growth, and carcass quality for broiler chickens. Poult. Sci. 70:746-755. doi:10.3382/ps.0700746

Welfare Quality. 2009. Assessment protocol for poultry. Welfare Quality. Wageningen, The Netherlands. p. 33-35. 